\title{
Efeitos da ractopamina e de dois níveis de lisina digestível na dieta sobre o desempenho e características de carcaça de leitoas em terminação
}

[Effects of ractopamine and two lysine levels on performance and carcass traits of gilts in the finishing phase]

\author{
F.A. Pereira ${ }^{1}$, D.O. Fontes ${ }^{2 *}$, F.C.O. Silva ${ }^{3}$, W.M. Ferreira ${ }^{2}$, A.M.Q. Lanna ${ }^{2}$, G.S.S. Corrêa ${ }^{2}$, \\ M.A. Silva ${ }^{2}$, P.C. Marinho ${ }^{1}$, C.L.C. Arouca ${ }^{1}$, G.M. Salum ${ }^{4}$ \\ ${ }^{1}$ Aluno de pós-graduação - EV-UFMG - Belo horizonte, MG \\ ${ }^{2}$ Escola de Veterinária - UFMG \\ Caixa Postal 567 \\ 31270-901 - Belo Horizonte, MG \\ ${ }^{3}$ EPAMIG - Viçosa, MG \\ ${ }^{4}$ Aluno de graduação EV-UFMG - Belo Horizonte, MG
}

\begin{abstract}
RESUMO
Avaliaram-se os efeitos da ractopamina e de dois níveis de lisina digestível na dieta sobre o desempenho e características de carcaça de leitoas com peso corporal a partir de $85 \mathrm{~kg}$, durante 21 e 28 dias antes do abate, os quais foram distribuídos em delineamento experimental de blocos ao acaso com cinco repetições de dois animais por unidade experimental. Os tratamentos consistiram de arranjo fatorial $2 \times 2$, com dois níveis de lisina digestível (LD), 0,67 e 0,87\%, e dois níveis de ractopamina ( 0 e 5ppm). Observou-se efeito significativo do nível de LD sobre o ganho de peso e peso corporal e interação significativa $(\mathrm{P}<0,05)$ entre o nível de LD e a ractopamina sobre a conversão alimentar e sobre a taxa de deposição de carne magra corporal. Não houve efeito significativo $(\mathrm{P}>0,05)$ do nível de LD sobre a espessura de toucinho, profundidade de lombo e rendimento em carne magra da carcaça de acordo com avaliação da carcaça, feita in vivo. Não houve efeito $(\mathrm{P}>0,05)$ da ractopamina sobre o consumo de ração, o ganho de peso diário e o peso corporal aos 21 e 28 dias de experimento. A ractopamina reduziu a espessura de toucinho no ponto P2 aos 21 dias e aumentou o rendimento de carne magra e a profundidade de lombo na avaliação da carcaça no frigorífico.
\end{abstract}

Palavras-chave: leitoa, carcaça, desempenho, ractopamina, lisina

\begin{abstract}
The effects of ractopamine and digestible lysine levels on performance and carcass traits of gilts with initial body weight average of $85 \mathrm{~kg}$, recorded during 21 and 28 day before slaughtering time were evaluated in a completely randomized block design with five replicates of two animals per experiment unit. The treatments consisted in a $2 \times 2$ factorial scheme, two levels of digestible lysine (DL) (0.67 and $0.87 \%$ ) and two ractopamine levels (0 and 5ppm). Significant effects of DL on daily weight gain and body weight and significant effects of $D L$ and ractopamine level were observed for feed:weight gain ratio and lean meat carcass deposition. No significant effects $(P>0.05)$ of DL on fat thickness, muscle depth and lean meat yield according to the in vivo carcass evaluation were observed. No significant effect of ractopamine $(P>0.05)$ on feed intake, daily weight gain and body weight (21 and 28 days) were observed. Ractopamine reduced back fat thickness at P2 point (21days) and increased lean meat yield and muscle depth in frigorific carcass evaluation.
\end{abstract}

Keywords: gilt, carcass, performance, ractopamine, lysine

Recebido em 18 de dezembro de 2007

Aceito em 27 de junho de 2008

*Autor para correspondência (corresponding author)

E-mail: dalton@vet.ufmg.br 


\section{INTRODUÇÃO}

Para satisfazer a demanda do mercado consumidor, as empresas de melhoramento genético têm se preocupado em produzir linhagens sintéticas visando ao incremento da produção de carne em detrimento da produção de gordura (Arouca et al., 2004), e o nutricionista tem buscado alternativas que favoreçam $o$ desempenho sem prejudicar o produto final, que sejam mais seguras e mais aceitáveis pela sociedade (Gomes et al., 2007).

A ractopamina é um repartidor de nutrientes que apresenta características químicas e atividade semelhante à de hormônios da adrenal, classificada como uma fenetanolamina. As fenetanolaminas são freqüentemente denominadas de repartidores de nutrientes, devido a sua capacidade de redistribuir os nutrientes em função da alteração do metabolismo celular. Há um redirecionamento dos nutrientes que seriam destinados da síntese e deposição de lípides para a deposição de tecido muscular. Estes compostos têm ação com intensidade variável de acordo com a espécie, sendo que os suínos são bastante sensíveis (Vasconcelos et al., 2007).

A ractopamina tem se demonstrado capaz de melhorar o desempenho e as características de carcaça de suínos por meio de aumento do percentual de carne magra na carcaça (Zagury, 2002). Entretanto, para que seu uso proporcione efeitos desejáveis, parece haver a necessidade de ajustes nutricionais nas dietas, porque os suínos suplementados com ractopamina apresentarão maior taxa de deposição protéica, em decorrência, exigirão maior quantidade de aminoácidos.

A lisina tem sido considerada o primeiro aminoácido limitante na dieta de suínos à base de milho e farelo de soja por ser exigida em maior quantidade para deposição de carne e em razão do destino metabólico para deposição de tecido magro (Kessler, 1998). Apresenta função exclusiva de deposição de proteína corporal e manutenção, não estando envolvida em outros processos metabólicos (Corrêa et al. (2007a).

$\mathrm{O}$ ajuste de lisina e proteína da dieta às exigências dos animais pode, portanto, resultar em melhor eficiência alimentar (Arouca et al.,
2005), sem onerar os custos de produção, já que as fontes protéicas são os componentes de maior participação no custo das dietas (Corrêa et al., 2007b,c,d).

Com base nestes fatos, este experimento teve o objetivo de estudar os efeitos da ractopamina e de dois níveis de lisina digestível na dieta sobre parâmetros de desempenho e de carcaça, avaliados in vivo por ultra-som e no frigorífico, de leitoas em terminação a partir dos $85 \mathrm{~kg}$.

\section{MATERIAL E MÉTODOS}

O experimento foi realizado durante os meses de fevereiro e março de 2004. Foram utilizadas 40 leitoas comerciais ${ }^{1}$, originadas de linhagens selecionadas geneticamente para deposição de carne magra, com peso inicial de $85,17 \pm 0,39 \mathrm{~kg}$. Os animais foram distribuídos em um delineamento experimental de blocos ao acaso, sendo "tempo de início" o fator blocado, em arranjo fatorial $2 \times 2$, com dois níveis lisina digestível, 0,67 e $0,87 \%$ e ractopamina, 0 e $5 \mathrm{ppm}$, cinco repetições e dois animais por unidade experimental. Os animais foram identificados individualmente por meio de brincos nas orelhas para acompanhamento das carcaças no frigorífico e avaliados em dois períodos independentes, durante os 21 e 28 dias antecedentes ao abate.

As dietas experimentais, à base de milho e farelo de soja, suplementadas com vitaminas e minerais, foram formuladas para atender as exigências mínimas sugeridas por Rostagno et al. (2000).

Foram formuladas dietas com dois níveis de lisina digestível (LD), uma com $0,67 \%$, dietacontrole, e outra com $0,87 \%$, dieta ajustada com alto nível de lisina. O maior nível de $\mathrm{LD}$ foi obtido por meio da maior inclusão de farelo de soja, para que se atingisse o acréscimo desejado. O nível de $0,87 \%$ de LD foi estabelecido porque os animais tratados com ractopamina devem consumir $30 \%$ a mais de lisina para atingirem resultados significativos de desempenho e qualidade de carcaça (Mitchell et al., 1991; Xiao et al., 1999), conforme Tab. 1.

${ }^{1}$ Cruzamento de fêmea Camborough $22^{\circledR}$ com macho AgPic $412{ }^{\circledR}$ da Agroceres PIC .S.A. 
Tabela 1. Composição centesimal e valores nutricionais calculados das dietas experimentais para leitoas de acordo com diferentes tratamentos

\begin{tabular}{|c|c|c|c|c|}
\hline \multirow{2}{*}{ Ingredientes } & \multicolumn{4}{|c|}{ Nível de lisina digestível (\%)/nível de ractopamina (ppm) } \\
\hline & $0,67 / 0,00$ & $0,67 / 5,00$ & $0,87 / 0,00$ & $0,87 / 5,00$ \\
\hline Milho & 75,63 & 75,63 & 66,33 & 66,33 \\
\hline Farelo de soja & 21,11 & 21,11 & 30,20 & 30,20 \\
\hline Fosfato bicálcico & 1,19 & 1,19 & 1,13 & 1,13 \\
\hline Calcário & 0,82 & 0,82 & 0,79 & 0,79 \\
\hline Sal & 0,40 & 0,40 & 0,40 & 0,40 \\
\hline Óleo de soja & 0,00 & 0,00 & 0,30 & 0,30 \\
\hline Suplemento vitamínico ${ }^{1}$ & 0,30 & 0,30 & 0,30 & 0,30 \\
\hline Suplemento mineral $^{2}$ & 0,10 & 0,10 & 0,10 & 0,10 \\
\hline Promotor de crescimento ${ }^{*}$ & 0,08 & 0,08 & 0,08 & 0,08 \\
\hline Suplemento de cobre ${ }^{3}$ & 0,04 & 0,04 & 0,04 & 0,04 \\
\hline Cloridrato de ractopamina** & 0,00 & 0,03 & 0,00 & 0,03 \\
\hline Inerte & 0,33 & 0,32 & 0,325 & 0,32 \\
\hline Total & 100 & 100 & 100 & 100 \\
\hline \multicolumn{5}{|c|}{ Valor nutricional calculado*** } \\
\hline Energia metabolizável (Mcal/kg) & 3,18 & 3,18 & 3,18 & 3,18 \\
\hline Proteína bruta (\%) & 16,10 & 16,10 & 19,44 & 19,44 \\
\hline Cálcio (\%) & 0,70 & 0,70 & 0,70 & 0,70 \\
\hline Fósforo disponível (\%) & 0,32 & 0,32 & 0,32 & 0,32 \\
\hline Lisina digestível (\%) & 0,67 & 0,67 & 0,87 & 0,87 \\
\hline Metionina+cistina digestível (\%) & 0,49 & 0,49 & 0,56 & 0,56 \\
\hline Treonina digestível (\%) & 0,52 & 0,52 & 0,63 & 0,63 \\
\hline Triptofano digestível (\%) & 0,16 & 0,16 & 0,21 & 0,21 \\
\hline Ractopamina & 0ppm & $5 \mathrm{ppm}$ & $0 \mathrm{ppm}$ & $5 \mathrm{ppm}$ \\
\hline
\end{tabular}

${ }^{1}$ Níveis de garantia (kg/produto): ácido fólico: 116,55mg; ácido pantotênico: 2.333,5mg; biotina: 5,28mg; niacina: 5.600mg; piridoxina: $175 \mathrm{mg}$; riboflavina: $933,3 \mathrm{mg}$; tiamina: $175 \mathrm{mg}$; vit. A: $1.225 .000 \mathrm{UI}$; vit. $\mathrm{D}_{3}: 315.000 \mathrm{UI}$; vit. E: $1.400 \mathrm{mg}$; vit. $\mathrm{K}_{3}: 700 \mathrm{mg}$; vit. $\mathrm{B}_{12}: 6.825 \mathrm{mg}$; selênio: $105 \mathrm{mg}$; antioxidante: $1.500 \mathrm{mg}$.

${ }^{2}$ Níveis de garantia (kg/produto): cálcio: $98.800 \mathrm{mg}$; cobalto: $185 \mathrm{mg}$; cobre: $15,750 \mathrm{mg}$; ferro: $26.250 \mathrm{mg}$; iodo: $1.470 \mathrm{mg}$; manganês: $41.850 \mathrm{mg}$; zinco: $77.999 \mathrm{mg}$.

${ }^{3}$ Níveis de garantia (kg/produto): cobre: 150mg; zinco: 100mg; * Tylan ${ }^{\circledR}$ - Tilosina; ** Paylean ${ }^{\circledR}$ - cloridrato de ractopamina; *** Segundo Rostagno et al.(2000).

As rações experimentais e as sobras foram pesadas duas vezes por semana durante o período experimental; os animais foram individualmente pesados, no início, aos 21 dias e ao final do período experimental (28 dias), quando foram determinados o peso aos 21 dias de experimento (P21), o peso final (PF), o ganho de peso diário (GPD), a conversão alimentar (CA), o consumo de ração diário (CRD) e o consumo de lisina digestível diário (CLD).

Para a avaliação da carcaça in vivo, foram tomadas medidas de ultra-som para algumas das características de carcaça no início, aos 21 dias e aos 28 dias de experimento, após as pesagens dos animais, utilizando-se um equipamento portátil de ultra-som ${ }^{2}$. As medidas avaliadas foram espessura de toucinho tomada no ponto P1 (ET$\mathrm{P} 1)$, espessura de toucinho tomada no ponto P2 (ET-P2), porcentagem de carne magra na carcaça (PCM) e deposição de carne magra na carcaça (DCM). A metodologia utilizada para esse procedimento foi obtida segundo Arouca et al. (2004).

Ao final do período experimental, após a pesagem, os animais permaneceram em jejum por 14 horas. No dia seguinte, foram pesados para obtenção do peso em jejum e encaminhados para abate.

\footnotetext{
${ }^{2}$ PigLog- $105^{\circledR}-$ Herlev, Dinamarca.
} 
Para a avaliação das características de carcaça, pesou-se a carcaça quente, sem cabeça, focinho, papadas, orelhas e pés. $\mathrm{O}$ rendimento de carcaça foi obtido por meio da relação percentual entre o peso vivo do animal em jejum e o peso da carcaça quente. A pesagem da carcaça fria foi realizada após permanecerem entre 16 e 20 horas na câmara fria, à temperatura de 2 a $4^{\circ} \mathrm{C}$. O rendimento de pernil foi obtido por meio da relação percentual entre o peso da carcaça resfriada e o peso dos dois pernis somados. O pernil foi separado de acordo com o corte do frigorífico. O rendimento de carré foi obtido por meio da relação percentual entre o peso da carcaça resfriada e o peso dos dois carrés somados, sendo este separado de acordo com o frigorífico. A espessura de toucinho, profundidade de lombo e porcentagem de carne magra foram obtidas por meio da utilização de uma sonda (HGP4 - Hennessy). A espessura de toucinho e a profundidade de lombo foram medidas em uma das meia carcaça no ponto correspondente à projeção perpendicular da última costela sobre o músculo longíssimo dorsal a $4 \mathrm{~cm}$ da coluna vertebral. Pelos dados de espessura de toucinho e da profundidade de lombo foi calculada a porcentagem de carne magra da carcaça segundo a equação contida no software do aparelho.
Os dados de desempenho, das medidas de ultrasom in vivo e das características de carcaça foram submetidos à análise de variância utilizando o pacote computacional SAEG (Sistema..., 2000).

Para os resultados das medidas de ultra-som in vivo, espessura de toucinho, profundidade de lombo e porcentagem de carne magra, utilizou-se como covariável o resultado correspondente à mesma variável no início do experimento. Quando houve interação entre os níveis de ractopamina e os de lisina, a média dos tratamentos foi comparada pelo teste Fisher ao nível de 5\% de probabilidade.

\section{RESULTADOS E DISCUSSÃO}

Os resultados de consumo de ração, de consumo de lisina digestível, ganho de peso e peso corporal das leitoas submetidas a dietas suplementadas com dois níveis de lisina digestível $(0,67$ e $0,87 \%)$ são apresentados na Tab. 2. Não houve interação significativa entre os níveis de LD e de ractopamina sobre o consumo diário de ração, consumo diário de lisina digestível, ganho de peso diário e peso corporal, aos 21 e 28 dias de experimento.

Tabela 2. Consumo diário de ração e de lisina digestível, ganho de peso diário e peso corporal, de leitoas em terminação, alimentadas com dietas contendo diferentes níveis de lisina digestível, aos 21 e 28 dias de experimento

\begin{tabular}{lcccccc}
\hline \multicolumn{1}{c}{ Parâmetro } & \multicolumn{3}{c}{21 dias } & \multicolumn{3}{c}{28 dias } \\
\cline { 2 - 7 } & $0,67 \%$ & $0,87 \%$ & $\mathrm{CV}(\%)$ & $0,67 \%$ & $0,87 \%$ & $\mathrm{CV}(\%)$ \\
\hline Consumo de ração (kg/dia) & $2,59 \mathrm{~b}$ & $2,84 \mathrm{a}$ & 4,8 & $2,65 \mathrm{~b}$ & $2,89 \mathrm{a}$ & 5,1 \\
Consumo de lisina (g/dia) & $17,38 \mathrm{~b}$ & $24,85 \mathrm{a}$ & 4,5 & $17,75 \mathrm{~b}$ & $25,31 \mathrm{a}$ & 4,7 \\
Ganho de peso (kg/dia) & $1,02 \mathrm{~b}$ & $1,22 \mathrm{a}$ & 6,7 & $1,01 \mathrm{~b}$ & $1,21 \mathrm{a}$ & 6,7 \\
Peso corporal (kg) & $106,56 \mathrm{~b}$ & $110,89 \mathrm{a}$ & 1,7 & $113,50 \mathrm{~b}$ & $118,95 \mathrm{a}$ & 2,1 \\
\hline
\end{tabular}

Médias seguidas de letras distintas na linha diferem entre si pelo teste Fisher $(\mathrm{P}<0,01)$.

Houve efeito do nível de lisina digestível sobre consumo diário de ração e consumo diário de lisina digestível, aos 21 e 28 dias de tratamento $(\mathrm{P}<0,01)$. O consumo diário de ração foi maior, aproximadamente $250 \mathrm{~g}$, para os animais que receberam a dieta com $0,87 \%$ de $\mathrm{LD}$ e, conseqüentemente, o consumo de lisina digestível foi de 7,5g/dia maior que o grupo alimentado com a dieta formulada com $0,67 \%$ de LD.
Mitchell et al. (1991), ao avaliarem os efeitos de dois níveis de proteína bruta (12 e 15\%) sobre o desempenho de suínos submetidos a dietas suplementadas com ractopamina, observaram maior consumo de ração para os animais tratados com a dieta contendo alta proteína bruta. Os animais tratados com $12 \%$ de PB consumiram $15 \%$ menos ração que os tratados com $18 \%$ de PB.

Observou-se efeito do nível de LD sobre o ganho de peso diário aos 21 e 28 dias de 
tratamento $(\mathrm{P}<0,01)$. O ganho de peso foi, em média, $20 \%$ maior do que o de grupo que consumiu a ração com $0,87 \%$ de $\mathrm{LD}$, correspondendo a um aumento de aproximadamente $200 \mathrm{~g} / \mathrm{dia}$ aos 21 e 28 dias de experimento. Da mesma forma, Dunshea et al. (1993b) avaliaram dietas com 0 e 20ppm de ractopamina e seis níveis dietéticos de lisina, para fêmeas suínas em terminação e observaram aumento no ganho de peso em função do aumento do nível de lisina. Marinho et al. (2005a), ao estudarem o efeito de dietas com dois níveis de lisina digestível, 0,67 e 0,87\%, e dois níveis de ractopamina, sobre o ganho de peso diário de suínos machos castrados a partir dos $85 \mathrm{~kg}$ de peso, não observaram efeito do nível de LD sobre o ganho de peso dos animais. Os níveis utilizados por esses autores excederam as exigências sugeridas por Rostagno et al. (2005) para esta categoria de animais. Segundo Marinho et al. (2005a), o menor nível de lisina avaliado atendeu as exigências dos animais, por isso não observaram efeitos da elevação dos níveis de LD no trabalho. Entretanto, Rostagno et al. (2005) recomendam para leitoas níveis de LD superiores aos sugeridos para machos castrados, entre 20 e $14 \mathrm{~g}$ por dia de LD para leitoas entre 85 e $108 \mathrm{~kg}$ de peso, valores esses, que estão dentro dos níveis estudados neste trabalho. O aumento no ganho de peso das leitoas suplementadas com $0,87 \%$ de LD sugere que a exigência desses animais está mais próxima dos $0,87 \%$ de $\mathrm{LD}$, para leitoas de alta capacidade de deposição de carne magra na carcaça.

Os animais tratados com dietas contendo $0,87 \%$ de LD apresentaram aumento no peso final $(\mathrm{P}<0,01)$ de 4,0 e $5,4 \mathrm{~kg}$, correspondendo a uma melhora de 4,0 e 4,8\%, aos 21 e 28 dias, respectivamente. Apple et al. (2004) avaliaram os efeitos de três níveis de lisina em dietas suplementadas com 10ppm de ractopamina e verificaram aumento do peso corporal de suínos, de ambos os sexos, em função da elevação no nível de lisina na dieta. Entretanto, Marinho et al. (2005a) não observaram efeito do nível de lisina digestível sobre o peso corporal de suínos machos castrados.

A suplementação com ractopamina $(5 \mathrm{ppm})$ nas dietas de leitoas em terminação não influenciou $(\mathrm{P}>0,05)$ os parâmetros de desempenho aos $21 \mathrm{e}$ 28 dias de tratamento (Tab. 3 ).

Tabela 3. Consumo diário de ração e de lisina digestível, ganho de peso diário e peso corporal, de leitoas em terminação, em dietas suplementadas ou não com ractopamina, aos 21 e 28 dias de experimento

\begin{tabular}{lcccccc}
\hline \multicolumn{1}{c}{ Parâmetro } & \multicolumn{3}{c}{21 dias } & \multicolumn{3}{c}{28 dias } \\
\cline { 2 - 7 } & 0 & $5 \mathrm{ppm}$ & $\mathrm{CV}(\%)$ & 0 & $5 \mathrm{ppm}$ & $\mathrm{CV}(\%)$ \\
\hline Consumo de ração (kg/dia) & 2,76 & 2,67 & 4,8 & 2,81 & 2,73 & 5,1 \\
Consumo de lisina (g/dia) & 21,49 & 20,74 & 4,5 & 21,84 & 21,21 & 4,7 \\
Ganho de peso (kg/dia) & 1,10 & 1,13 & 6,7 & 1,12 & 1,00 & 6,7 \\
Peso corporal (kg) & 108,58 & 108,87 & 1,7 & 116,33 & 116,13 & 2,1 \\
\hline
\end{tabular}

Não se observou efeito da ractopamina sobre o consumo de ração e de lisina digestível $(\mathrm{P}>0,05)$. Xiao et al. (1999) também não observaram alterações no consumo dos animais submetidos à ractopamina. Entretanto, Pozza et al. (2003), ao avaliarem os efeitos da ractopamina sobre $o$ desempenho de suínos machos castrados e fêmeas na fase de terminação, observaram redução no consumo de alimento dos animais. Os autores sugeriram que as altas temperaturas ocorridas durante o período experimental poderiam ter sido a causa da redução no consumo de ração dos animais suplementados com ractopamina.
O ganho de peso diário das leitoas não foi influenciado pela suplementação de ractopamina nas dietas aos 21 e 28 dias de tratamento ( $>>0,05)$. Pozza et al. (2003) não observaram efeito significativo sobre o ganho de peso de leitoas submetidas à ractopamina, enquanto Xiao et al. (1999) e Marinho et al. (2005a) observaram aumento no ganho de peso diário, de aproximadamente $10 \%$, para os animais tratados com ractopamina.

A melhoria de ganho de peso diário de suínos machos castrados e de ambos os sexos agrupados, em resposta à ractopamina, tem sido comumente observada. Xiao et al. (1999) observaram interação entre o nível de proteína 
bruta e o nível de ractopamina sobre o ganho de peso de suínos em terminação. Para estes autores, no nível dietético de $13 \%$ de $\mathrm{PB}$, o tratamento com ractopamina não influenciou $o$ ganho de peso diário dos animais. Já para o nível de $18 \%$ de $\mathrm{PB}$ a suplementação de ractopamina melhorou o ganho de peso dos animais.

O peso corporal não foi influenciado pela suplementação das dietas com ractopamina aos 21 e 28 dias de tratamento $(\mathrm{P}>0,05)$, concordando com os resultados de Pozza et al. (2003) e diferindo dos de Xiao et al. (1999), Crome et al. (1996) e Marinho et al. (2005a). Embora os níveis de LD avaliados neste trabalho sejam semelhantes aos sugeridos por Rostagno et al. (2005) para leitoas de alto potencial genético, parece que o nível de $0,87 \%$ de LD não atendeu ao potencial de crescimento desses animais, quando estas foram suplementadas com $5 \mathrm{ppm}$ de ractopamina. Do mesmo modo que observado por Zagury (2002), o nível de LD pode ter limitado o aumento no ganho de peso diário das leitoas, quando submetidas à ractopamina.

Houve efeito da interação $(\mathrm{P}<0,05)$ entre níveis de ractopamina versus nível de LD sobre a conversão alimentar de leitoas a partir de $85 \mathrm{~kg}$ de peso (Tab. 4). Para o nível de $0,67 \%$ de LD, não houve efeito $(\mathrm{P}>0,05)$ da suplementação com ractopamina, entretanto, para $0,87 \%$, a melhor conversão ocorreu no grupo tratado com $5 \mathrm{ppm}$ de ractopamina. A melhora na conversão alimentar foi de $15,8 \%$ aos 21 , e de $13,8 \%$, aos 28 dias de tratamento. Efeitos positivos da ractopamina sobre o desempenho de suínos também foram relatados por Crome et al. (1996), que observaram melhora de $13,9 \%$ na eficiência alimentar de suínos abatidos aos $107 \mathrm{~kg}$ e $18,6 \%$ para animais aos $125 \mathrm{~kg}$, tratados com $10 \mathrm{e}$ 20ppm de ractopamina.

Tabela 4. Conversão alimentar de leitoas submetidas a dois níveis de lisina digestível, e ractopamina na dieta aos 21 e 28 dias de tratamento

\begin{tabular}{|c|c|c|c|c|}
\hline \multirow{2}{*}{$\begin{array}{c}\text { Nível de lisina } \\
\text { digestível }\end{array}$} & \multicolumn{2}{|c|}{21 dias } & \multicolumn{2}{|c|}{28 dias } \\
\hline & 0 & $5 \mathrm{ppm}$ & 0 & $5 \mathrm{ppm}$ \\
\hline $0,67 \%$ & $2,53 \mathrm{Bb}$ & $2,59 \mathrm{Bb}$ & $2,57 \mathrm{Bb}$ & $2,65 \mathrm{Bb}$ \\
\hline $0,87 \%$ & $2,49 \mathrm{Bb}$ & $2,19 \mathrm{Aa}$ & $2,54 \mathrm{Bb}$ & $2,28 \mathrm{Aa}$ \\
\hline $\mathrm{CV}(\%)$ & \multicolumn{2}{|c|}{7,0} & \multicolumn{2}{|c|}{6,0} \\
\hline
\end{tabular}

Médias seguidas de letras, minúsculas na linha e maiúsculas na coluna, diferem entre si pelo teste Fisher $(\mathrm{P}<0,05)$

Os resultados deste trabalho confirmam os obtidos por Uttaro et al. (1996), Zagury (2002) e Marinho et al. (2005a), que demonstraram que a conversão alimentar é um dos principais parâmetros melhorados pelo uso de substâncias repartidoras de nutrientes, como a ractopamina. A melhora de a eficiência alimentar ocorre devido a um favorecimento de deposição de proteína na carcaça, com economia energética para o metabolismo animal. A síntese de tecido adiposo é mais dispendiosa energeticamente que a síntese de tecido muscular em função da grande inclusão de moléculas de água, ocorrida na construção do tecido muscular. Embora Dunshea et al. (1993a) tenham verificado a ocorrência de maior mobilização do tecido adiposo e não uma redução na lipogênese, a maior disponibilidade energética ocorre por direcionamento do fluxo metabólico de energia para o tecido muscular.
Segundo a avaliação de carcaça in vivo por ultrasom, não ocorreu interação $(\mathrm{P}>0,05)$ nível de lisina digestível versus nível de ractopamina sobre as características avaliadas. Os resultados de espessura de toucinho, profundidade de lombo e deposição de carne magra na carcaça, em função de nível de lisina digestível, aos 21 e 28 dias de tratamento, encontram-se na Tab. 5.

Não foram observados efeitos do nível de LD sobre a espessura de toucinho, medida no ponto P1 e P2 ( $>0,05)$. Resultados semelhantes foram obtidos por Marinho et al. (2005b), que trabalharam com machos castrados, e por See et al. (2004), que estudaram suínos de ambos os sexos. Entretanto, Apple et al. (2004), ao avaliarem três níveis de lisina e dois níveis de energia metabolizável para suínos submetidos à ractopamina, observaram efeito linear do nível de lisina sobre a espessura de toucinho, obtida por ultra-som. 
Tabela 5. Espessura de toucinho nos pontos $\mathrm{P}_{1}$ e $\mathrm{P}_{2}$, profundidade de lombo, rendimento em carne magra e deposição de carne magra diária, de leitoas em terminação, alimentadas com dois níveis de lisina digestível, obtidos in vivo, aos 21 e 28 dias de experimento

\begin{tabular}{lcccccc}
\hline \multicolumn{1}{c}{ Parâmetro } & \multicolumn{3}{c}{21 dias } & \multicolumn{3}{c}{28 dias } \\
\cline { 2 - 7 } & $0,67 \%$ & $0,87 \%$ & CV $(\%)$ & $0,67 \%$ & $0,87 \%$ & CV (\%) \\
\hline Espessura de toucinho P1 (mm)* & 13,57 & 13,78 & 11,1 & 14,04 & 14,56 & 11,6 \\
Espessura de toucinho P2 (mm)* & 10,42 & 10,63 & 10,0 & 10,98 & 11,32 & 13,9 \\
Profundidade de lombo (mm)* & 55,27 & 56,82 & 7,5 & 57,72 & 60,08 & 9,1 \\
Rendimento em carne magra (\%)* & 59,18 & 59,96 & 3,0 & 59,12 & 59,53 & 3,4 \\
Deposição de carne magra (g/dia) & $595,59 \mathrm{~b}$ & $748,55 \mathrm{a}$ & 16,7 & $585,74 \mathrm{~b}$ & $725,39 \mathrm{a}$ & 12,8 \\
\hline
\end{tabular}

Médias seguidas de letras distintas na linha diferem entre si pelo teste Fisher $(\mathrm{P}<0,01)$.

*Medidas ajustadas de acordo com a covariável - valor correspondente à mesma variável no início do experimento.

A profundidade do lombo não foi influenciada pelo nível de LD $(\mathrm{P}>0,05)$. Da mesma forma, Kill et al. (2003a,b) e Adeola et al. (1990) não encontraram efeito do nível de lisina sobre a profundidade do lombo. Entretanto, Xiao et al. (1999) observaram aumento na área de olho de lombo de 4,2\% para os animais submetidos às dietas com alta PB e suplementados com ractopamina na dosagem de $20 \mathrm{ppm}$.

Não foi observado efeito do nível de LD sobre o rendimento em carne magra da carcaça $(\mathrm{P}>0,05)$. Resultados semelhantes foram obtidos por Marinho et al. (2005b) e por Kill et al. (2003a).
Houve efeito do nível de $\mathrm{LD}(\mathrm{P}<0,01)$ sobre de deposição de carne magra na carcaça. A deposição de carne magra foi maior 152 e $139 \mathrm{~g} /$ dia aos 21 e 28 dias, respectivamente, para o nível de $0,87 \%$ de LD. Resultados semelhantes foram relatados por Marinho et al. (2005b), em suínos machos castrados alimentados por dieta com $0,87 \%$ de LD.

Os resultados de espessuras de toucinho nos pontos $\mathrm{P}_{1}$ e $\mathrm{P}_{2}$, profundidade de lombo, rendimento em carne magra e taxa de deposição de carne magra diária, de leitoas em terminação, alimentadas com dietas suplementadas ou não com ractopamina, obtidos in vivo, aos 21 e 28 dias de experimento são apresentados na Tab. 6.

Tabela 6. Espessura de toucinho nos pontos $\mathrm{P}_{1}$ e $\mathrm{P}_{2}$, profundidade de lombo, rendimento em carne magra e deposição de carne magra diária, de leitoas em terminação, alimentadas com dietas suplementadas ou não com ractopamina, obtidos in vivo, aos 21 e 28 dias de experimento

\begin{tabular}{lcccccc}
\hline \multicolumn{1}{c}{ Parâmetro } & \multicolumn{3}{c}{21 dias } & \multicolumn{3}{c}{28 dias } \\
\cline { 2 - 7 } & 0 & $5 \mathrm{ppm}$ & $\mathrm{CV}(\%)$ & 0 & $5 \mathrm{ppm}$ & $\mathrm{CV}(\%)$ \\
\hline Espessura de toucinho P1 (mm)* & 13,86 & 13,49 & 11,1 & 14,17 & 14,43 & 11,6 \\
Espessura de toucinho P2 (mm)* & $11,00 \mathrm{~b}$ & $10,03 \mathrm{a}$ & 10,0 & 11,35 & 10,95 & 13,9 \\
Profundidade de lombo (mm)* & 55,84 & 56,26 & 7,5 & 58,79 & 59,01 & 9,1 \\
Rendimento em carne magra (\%)* & 59,25 & 59,88 & 3,0 & 59,25 & 59,39 & 3,4 \\
Deposição de carne magra (g/dia) & 650,88 & 693,26 & 16,7 & 642,85 & 668,27 & 12,8 \\
\hline
\end{tabular}

Médias seguidas de letras distintas na linha diferem entre si pelo teste Fisher $(\mathrm{P}<0,01)$.

*Medidas ajustadas de acordo com a covariável - valor correspondente à mesma variável no inicio do experimento.

Não houve efeito $(\mathrm{P}>0,05)$ da ractopamina sobre os parâmetros de carcaça avaliados in vivo por ultra-som, exceto para a espessura de toucinho no ponto $\mathrm{P} 2(\mathrm{P}<0,01)$, aos 21 dias, que foi reduzida em um ponto percentual. Os resultados estão de acordo com Marinho et al. (2005b), que também não observaram efeito da ractopamina sobre as características de carcaça. Do mesmo modo, Adeola et al. (1990), que trabalharam com suínos em terminação, alimentados com dieta suplementada com 20ppm de ractopamina, durante 28 dias, não observaram efeito significativo da adição de ractopamina sobre as características de carcaça.

Uttaro et al. (1993) obtiveram redução de 1,8mm na espessura de toucinho e aumento de $3,4 \mathrm{~mm}$ na área de lombo. Esses autores relataram que as leitoas apresentaram menor espessura de toucinho que os machos castrados. 
Os resultados da avaliação de carcaças em frigorífico, em função do nível de lisina digestível, encontram-se na Tab. 7. Para essas características da carcaça, não houve interação $(\mathrm{P}>0,05)$ entre o nível de lisina versus nível de ractopamina.

Não se observou efeito $(\mathrm{P}>0,05)$ do nível de lisina digestível sobre os parâmetros de carcaça das leitoas, avaliadas em frigorífico. Da mesma forma, Marinho et al. (2005b) observaram que os níveis de lisina digestível não influenciaram o rendimento de carcaça, rendimento de pernil, rendimento de carré, espessura de toucinho, medidos na altura da última costela e porcentagem de carne magra na carcaça de suínos machos castrados submetidos a dois níveis de lisina digestível e dois níveis de ractopamina.

Os resultados de rendimento de carcaça, rendimento de pernil, rendimento de carré, espessura de toucinho, profundidade de lombo e rendimento em carne magra na carcaça das leitoas submetidas a dietas suplementadas com ractopamina são apresentados na Tab. 8 .

Tabela 7. Rendimento de carcaça, de pernil, e de carré, espessura de toucinho medida na altura da última costela, profundidade de lombo e rendimento em carne magra na carcaça de leitoas em terminação, alimentadas com dois níveis de lisina digestível

\begin{tabular}{lccc}
\multicolumn{1}{c}{ Parâmetro } & $0,67 \%$ & $0,87 \%$ & $\mathrm{CV}(\%)$ \\
\hline Rendimento carcaça (\%) & 72,26 & 72,69 & 4,2 \\
Rendimento pernil (\%) & 34,94 & 34,82 & 3,1 \\
Rendimento carré (\%) & 12,93 & 12,90 & 7,2 \\
Espessura toucinho (mm) & 11,11 & 12,04 & 17,5 \\
Profundidade de lombo (mm) & 68,62 & 67,64 & 7,5 \\
Rendimento em carne magra da carcaça (\%) & 59,82 & 59,05 & 2,4 \\
\hline
\end{tabular}

Tabela 8. Rendimento de carcaça, de pernil e de carré, espessura de toucinho na altura da última costela, profundidade de lombo e rendimento em carne magra na carcaça de leitoas em terminação, suplementadas ou não com ractopamina

\begin{tabular}{lccc}
\hline \multicolumn{1}{c}{ Parâmetro } & 0 & $5 \mathrm{ppm}$ & $\mathrm{CV}(\%)$ \\
\hline Rendimento carcaça (\%) & 72,24 & 72,70 & 4,2 \\
Rendimento pernil (\%) & 34,72 & 35,05 & 3,1 \\
Rendimento carré (\%) & 12,78 & 13,06 & 7,2 \\
Espessura toucinho (mm) & 12,06 & 11,09 & 17,5 \\
Profundidade de lombo* (mm) & $66,84 \mathrm{~B}$ & $69,42 \mathrm{~A}$ & 7,5 \\
Rendimento carne magra da carcaça (\%) & $58,91 \mathrm{~b}$ & $59,97 \mathrm{a}$ & 2,4 \\
\hline
\end{tabular}

Médias seguidas de letras distintas, maiúsculas e minúsculas na linha diferem entre si pelo teste Fisher com $\mathrm{P}<0,06$ e $\mathrm{P}<0,05$, respectivamente.

Não houve efeito $(\mathrm{P}>0,05)$ da ractopamina sobre o rendimento de carcaça, rendimento de pernil, rendimento de carré e espessura de toucinho. Resultados semelhantes foram verificados por Marinho et al. (2005b), entretanto, esses autores encontraram efeitos sobre o rendimento de pernil. O aumento no rendimento de pernil também foi mostrado por Crome et al. (1996), em função da suplementação com ractopamina $(0,10$ e 20ppm).

Para essa metodologia de avaliação de carcaça, o rendimento em carne magra e a profundidade de lombo foram melhorados pela suplementação de ractopamina, em $3,9 \%$ e 1,8 pontos percentuais, respectivamente, diferentemente da avaliação in vivo, na qual as medidas finais foram corrigidas pela covariável (medida inicial).

Budiño et al. (2005) observaram aumento no peso das carcaças, redução da espessura de toucinho e aumento da área de olho de lombo de suínos com capacidade de deposição de carne magra moderada, tratados com 10 e 20 ppm de ractopamina.

\section{CONCLUSÕES}

Leitoas em terminação alimentadas com dietas contendo $0,87 \%$ de lisina digestível e $5 \mathrm{ppm}$ de ractopamina apresentam melhores desempenho produtivo e características de carcaça. 


\section{REFERÊNCIAS BIBLIOGRÁFICAS}

ADEOLA, O.; DARKO, E.A.; HE, P. et al. Manipulation of porcine carcass composition by ractopamine. J. Anim. Sci., v.68, p.3633-3641, 1990.

APPLE, J.K.; MAXWELL, C.V.; BROWN, D.C. et al. Effects of dietary lysine and density on performance and carcass characteristics of finishing pigs fed ractopamine. J. Anim. Sci., v.82, p.3277-3287, 2004.

ARMSTRONG, T.A.; IVES, D.J.; WAGNER, S.R. et al. The effect of dietary ractopamine concentration and duration of feeding on growth performance, carcass characteristics, and meat quality of finishing pigs. J. Anim. Sci., v.82, p.3245-3253, 2004.

AROUCA, C.L.C.; FONTES, D.O.; FERREIRA, W.M. et al. Exigências de lisina, com base no conceito de proteína ideal, para suínos machos castrados, de 95 a $122 \mathrm{~kg}$, selecionados para deposição de carne magra. Arq. Bras. Med. Vet. Zootec., v.56, p.773-781, 2004.

AROUCA, C.L.C.; FONTES, D.O.; VELOSO, J.A.F. et al. Exigências de lisina, com base no conceito de proteína ideal, para suínos machos castrados, dos 96 aos $120 \mathrm{~kg}$, selecionados para eficiência de crescimento. Arq. Bras. Med. Vet. Zootec., v.57, p.104-111, 2005.

BUDIÑO, F. E. L.; THOMAZ, M.C.; NEME, et al., Efeito da adição de diferentes níveis e fontes de cloridrato de ractopamina, sobre $o$ desempenho e características da carcaça de suínos em terminação. In: CONGRESSO BRASILEIRO DE VETERINÁRIOS ESPECIALISTAS EM SUÍNOS, 12., 2005, Fortaleza. Anais..., Concórdia: Embrapa Suínos e Aves, 2005. p.333-334.

CORRÊA, G.S.S.; SILVA, M.A.; CORRÊA, A.B. et al. Desempenho de codornas de corte EV1 alimentadas com diferentes níveis de lisina na dieta. Arq. Bras. Med. Vet. Zootec., v.59, p.1545-1553, 2007a.

CORRÊA, G.S.S.; SILVA, M.A.; CORRÊA, A.B. et al. Exigência de proteína bruta e energia metabolizável em codornas de corte durante a fase de crescimento. Arq. Bras. Med. Vet. Zootec., v.59, p.488-494, $2007 \mathrm{~b}$.
CORRÊA, G.S.S.; SILVA, M.A.; CORRÊA, A.B. et al. Exigência de proteína bruta e energia metabolizável para codornas de corte EV1. Arq. Bras. Med. Vet. Zootec., v.59, p.797-804, 2007c.

CORRÊA, G.S.S.; SILVA, M.A.; CORRÊA, A.B. et al. Exigência de proteína bruta para codornas de corte EV1 em crescimento. Arq. Bras. Med. Vet. Zootec., v.59, p.1278-1286, 2007d.

CROME, P.K.; MCKEITH, F.K.; CARR, T.R. et al. Effect of ractopamine on growth performance, carcass composition, and cutting yields of pigs slaughtered at 107 and 125 kilograms. J. Anim. Sci., v.74, p.709-716, 1996.

CROMWELL, G.L.; CLINE, T.R.; CRENSHAW, J.D. et al., The dietary protein and as a rapid response criterion to determine the lysine requirement of pigs. J. Anim. Sci., v.71, p.1510-1519, 1993.

DUNSHEA, F.R.; KING, R.H.; CAMPBELL, R.G., et al. Interrelationships between sex and ractopamine on protein and lipid deposition in rapidly growing pigs. J. Anim. Sci., v.71, p.29192930, 1993a.

DUNSHEA, F.R.; KING, R.H.; CAMPBELL, R.G., et al. Interrelationships between dietary protein and ractopamine on protein and lipid deposition in finishing gilts. J. Anim. Sci., v.71, p.2931-2941, 1993b.

FONTES, D.O.; DONZELE, J.L.; FERREIRA, A.S. et al. Níveis de lisina para leitoas selecionadas geneticamente para deposição de carne magra, dos 60 aos 95kg. R. Bras. Zootec., v.29, p.784-793, 2000.

GOMES, F.E.; FONTES, D.O.; SALIBA, E.O.S. et al. Ácido fumárico e sua combinação com os ácidos butírico ou fórmico em dietas de leitões recém-desmamados. Arq. Bras. Med. Vet. Zootec., v.59, p.1270-1277, 2007.

KESSLER, A.M. Exigências nutricionais para máximo rendimento de carne em suínos. In: SIMPÓSIO SOBRE RENDIMENTO E QUALIDADE DE CARNE SUÍNA, 1998, Concórdia, Anais... Concórdia: Embrapa Suínos e Aves, 1998. p.18-25.

KILL， J.L.; DONZELE， J.L.; OLIVEIRA, R.F.M., et al, Níveis de lisina para leitoas com alto potencial genético para deposição de carne 
magra dos 65 aos 95kg. Rev. Bras. Zootec., v.32, p.1647-1656, 2003a.

KILL， J.L.; DONZELE， J.L.; OLIVEIRA, R.F.M. et al. Planos de nutrição para leitoas com alto potencial genético para deposição de carne magra dos 65 aos $105 \mathrm{~kg}$. Rev. Bras. Zootec., v.32, p.1330-1338, 2003 b.

MARINHO, P.C.; FONTES, D.O.; SILVA, F.C.O. et al. Efeito da ractopamina e de métodos de formulação sobre o desempenho de suínos machos castrados em terminação. In: CONGRESSO BRASILEIRO DE VETERINÁRIOS ESPECIALISTAS EM SUÍNOS, 12., 2005, Fortaleza. Anais..., Concórdia: Embrapa Suínos e Aves, 2005a. p.341-342.

MARINHO, P.C.; FONTES, D.O.; PEREIRA, F.A. et al., Efeito da ractopamina e de métodos de formulação sobre as características de carcaça de suínos machos castrados em terminação. In: CONGRESSO BRASILEIRO DE VETERINÁRIOS ESPECIALISTAS EM SUÍNOS, 12., 2005, Fortaleza. Anais..., Concórdia: Embrapa Suínos e Aves, 2005b. p.343-344.

MITCHELL, A.D.; SOLOMON, M.B.; STEELE, N.C. Influence of level of dietary protein or energy on effects of ractopamine in finishing swine. J. Anim. Sci., v.69, p.4487-4495, 1991.

POZZA, P.C.; NUNES, R.V.; SANTOS, M.S. et al. Efeito da ractopamina sobre o desempenho e características de carcaça de suínos machos castrados na fase de terminação. In: CONGRESSO BRASILEIRO DE VETERINÁRIOS ESPECIALISTAS EM SUÍNOS, 11., 2003, Goiânia. Anais..., Concórdia: Embrapa Suínos e Aves, 2003. p.289-290.
ROSTAGNO, H.S.; ALBINO, L.F.T.; DONZELE, J.L. et al. Tabelas brasileiras para aves e suínos. Composição de alimentos $\mathrm{e}$ exigências nutricionais. Viçosa: UFV, 2000. $141 \mathrm{p}$.

ROSTAGNO, H.S.; ALBINO, L.F.T. ; DONZELE, J.L. et al. Tabelas brasileiras para aves e suínos. Composição de alimentos $\mathrm{e}$ exigências nutricionais. Viçosa: UFV, 2005. $186 \mathrm{p}$.

SEE, M.T.; ARMSTRONG, T.A.; WELDON, W.C.; Effect of ractopamine feeding program on growth performance and carcass composition in finishing pigs. J. Anim. Sci., v.82 p.2474-2480, 2004.

SISTEMA de Análises Estatísticas. Versão 8.0. SAEG. Viçosa: UFV, 2000. 138p.

UTTARO, B.E.; BALL, R.O.; DICK, P. et al. Effect of ractopamine and sex on growth, carcass characteristics, processing yield, and meat quality characteristics of crossbred swine. $J$. Anim. Sci., v.71, p.2439-2449, 1996.

VASCONCELOS, C.H.F.; FONTES; D.O.; CORRÊA, G.S.S. et al. Ractopamina na alimentação de suínos. Cad. Tec. Vet. Zootec., v.53, p.86-108, 2007.

XIAO, R.J.; XU, Z.R.; CHEN, H.L. Effects of ractopamine at different dietary protein levels on growth performance and carcass characteristics in finishing pigs. Anim. Feed Sci. Technol., v.79, p.119-127, 1999.

ZAGURY, F.T.R. Efeito da ractopamina na ração sobre o crescimento, composição da carcaça e qualidade de carne de suínos. 2002. 46f. Tese (Doutorado) - Escola de Veterinária, Universidade Federal de Minas Gerais, Belo Horizonte. 